Article

\title{
An Investigation of Cutting Performance and Action Mechanism in Ultrasonic Vibration-Assisted Milling of Ti6Al4V Using a PCD Tool
}

\author{
Yongsheng $\mathrm{Su}^{1, *}$ and Liang $\mathrm{Li}^{2}$ \\ 1 School of Mechanical Engineering, Anhui Polytechnic University, Wuhu 241000, China \\ 2 College of Mechanical and Electrical Engineering, Nanjing University of Aeronautics \& Astronautics, \\ Nanjing 210016, China; liliang@nuaa.edu.cn \\ * Correspondence: sysh@ahpu.edu.cn
}

check for updates

Citation: Su, Y.; Li, L. An

Investigation of Cutting Performance and Action Mechanism in Ultrasonic Vibration-Assisted Milling of Ti6A14V Using a PCD Tool. Micromachines 2021, 12, 1319. https://doi.org/ $10.3390 / \operatorname{mi1} 2111319$

Academic Editor: Xichun Luo

Received: 5 October 2021

Accepted: 21 October 2021

Published: 28 October 2021

Publisher's Note: MDPI stays neutral with regard to jurisdictional claims in published maps and institutional affiliations.

Copyright: (c) 2021 by the authors. Licensee MDPI, Basel, Switzerland. This article is an open access article distributed under the terms and conditions of the Creative Commons Attribution (CC BY) license (https:// creativecommons.org/licenses/by/ $4.0 /)$.

\begin{abstract}
A polycrystalline diamond (PCD) tool is employed in cutting various titanium alloys because of its excellent properties. However, improving the cutting performance of titanium alloys is still a challenge. Here, an experimental investigation on the influence of ultrasonic vibration-assisted machining (UVAM) of Ti6Al4V titanium alloy on the cutting performance and action mechanism was studied using a PCD tool. Cutting force, machined surface, surface adhesion, and wear morphology were analyzed. The results indicated that UVAM can effectively improve cutting performance. It was found that there was serious adhesion and wear of slight fragments close to the cutting edge after ultrasonic-assisted dry milling. Furthermore, the action mechanism of UVAM in improving cutting performance was discussed and analyzed from the perspective of intermittent cutting.
\end{abstract}

Keywords: Ti6Al4V titanium alloy; UVAM; cutting force; surface roughness; action mechanism

\section{Introduction}

Currently, various types of titanium alloys have been increasingly used in aircraft, rockets, missiles, automobiles, ships, and biological materials; titanium alloys occupy an extremely important position because of their excellent properties [1-3]. However, the poor machinability of titanium alloys restricts their application to a large extent and results in lower machining efficiency and shorter tool life as compared with other conventional materials [4-6]. Therefore, it is of great significance to obtain high efficiency machining performance of titanium alloys and expand their application field.

Various methods to improve a titanium alloy's machinability include employing surface coating [7], a superhard tool [8], cryogenic lubrication [9], structure optimization of the tool [10], bionic surface texture [11], and micromachining processes [12-14], etc. In recent years, ultrasonic machining methods have been widely studied for improving cutting performance at home and abroad. Gao et al. [15] found that ultrasonic-assisted milling using a new cutting force model had great effects on reducing the cutting force as compared with conventional milling. Chen et al. [16] found that the method of ultrasonic machining of composites effectively decreased cutting temperature and improved machining quality. $\mathrm{Ni}$ et al. [17] studied the performance of TC4 alloy using a carbide cutter and the results indicated that the ultrasonic machining had a better effect in reducing surface roughness and cutting force than that of the common milling method under the same condition. $\mathrm{Ni}$ et al. [18] also found that better surface quality could be obtained using the UVAM method with or without MQL as compared with that of conventional milling (CM), which can contribute to reducing tool wear. Lu et al. [19] studied the influence of UVAM on titanium alloy and the results demonstrated that a combination of the high-speed ultrasonic vibration and high-pressure coolant had a positive effect on the cutting performance. It is well known that a polycrystalline diamond (PCD) tool has the characteristics of super hardness and excellent wear resistance. 
Some studies have reported that a PCD tool has superior properties of anti-friction, anti-wear, and anti-adhesion as compared with other common machining tools [20-24]. In order to reduce environmental pollution caused by using cutting fluid, dry cutting has been increasingly used in machining of titanium alloys, which can effectively reduce machining costs and avoid the environmental pollution from chip dust and harm to workshop personnel [25]. However, few studies have reported on the machinability of ultrasonic-assisted dry milling of titanium alloy using a PCD tool. In this study, we conduct a comparative investigation of the effect of two methods, i.e., CM and UVAM, on the cutting performance and action mechanism using a PCD tool in dry cutting.

\section{Experimental Methods and Materials}

The slot milling experiments of CM and UVAM are carried out on a milling machine under different machining parameters. In addition, the relevant measurement equipment and instruments used in the experiment include a dynamometer (Kistler, type 9257B, Winterthur, Switzerland), scanning electron microscope (Phenom X, Eindhoven, The Netherlands), and a Mahr surface roughometer (Perthometer M1, Mahr, Germany). The cutting test apparatus are shown in Figure 1.

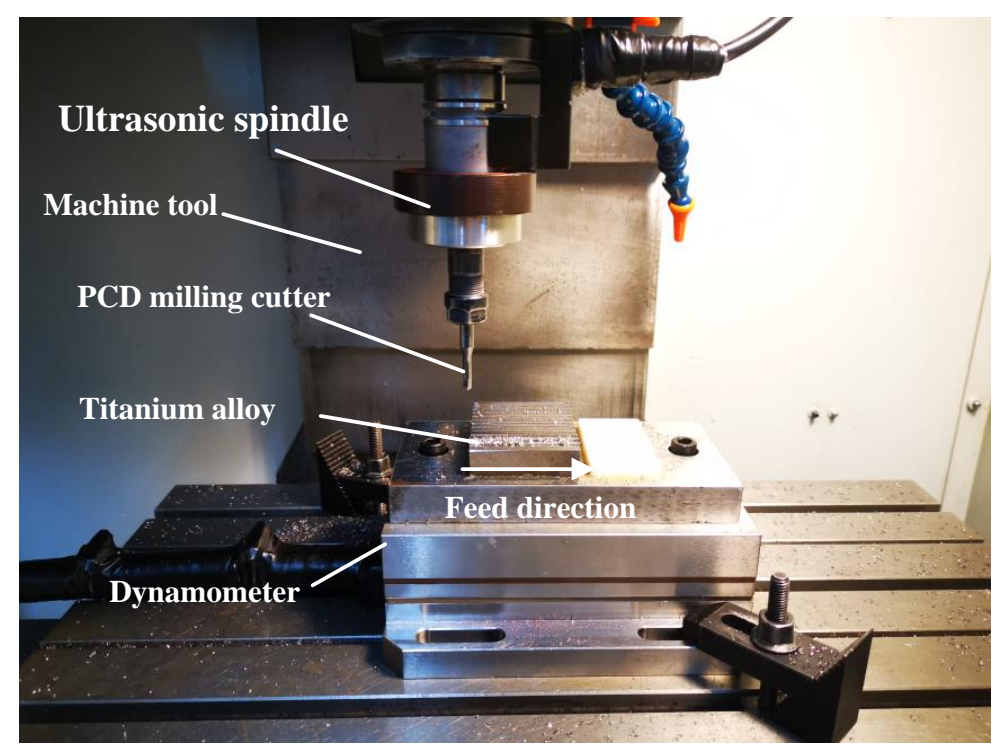

Figure 1. Cutting test apparatus.

The milling machine, workpiece, structure parameters of the tool, rake angle, clearance angle, cutting parameters, lubrication method, and parameters of UVAM used in the study are listed in Table 1.

Table 1. Cutting conditions.

\begin{tabular}{cc}
\hline Milling Machine & HAAS OM-2A \\
\hline Workpiece & Conventional Ti6Al4V \\
PCD tool & Rake angle $0^{\circ}$, relief angle $15^{\circ}$ \\
Tool diameter & $4 \mathrm{~mm}$ \\
Flutes & 2 \\
Spindle speed & $4000 \sim 10,000 \mathrm{rpm}$ \\
Depth of cut $\mathrm{a}_{\mathrm{p}}$ & $0.1 \sim 0.5 \mathrm{~mm}$ \\
Feed per tooth $\mathrm{f}_{\mathrm{z}}$ & $0.01 \sim 0.08 \mathrm{~mm} / \mathrm{z}$ \\
Lubrication method & Dry milling \\
Cutting length & $612 \mathrm{~mm}$ \\
Ultrasonic vibration direction & Axial direction \\
Ultrasonic frequency & $30 \mathrm{kHz}$ \\
Ultrasonic amplitude & $6 \mu \mathrm{m}$ \\
\hline
\end{tabular}




\section{Results and Discussion}

\subsection{The Influence of UVAM on Cutting Force}

In this part of the study, the values of selected $a_{p}, f_{z}$ and $n$ in Figure 2 were $0.3 \mathrm{~mm}$, $(0.03 \sim 0.08) \mathrm{mm} / \mathrm{z}$ and $6000 \mathrm{rpm}$, respectively. Similarly, the values of selected $\mathrm{a}_{\mathrm{p}}, \mathrm{f}_{\mathrm{z}}$ and $\mathrm{n}$ in Figure 3 were $(0.1 \sim 0.5) \mathrm{mm}, 0.03 \mathrm{~mm} / \mathrm{z}$ and $6000 \mathrm{rpm}$, respectively.

Figure 2 illustrates the influence of $\mathrm{f}_{\mathrm{z}}$ on the cutting force under the conditions of $\mathrm{CM}$ and UVAM, and the cutting forces of Fx, Fy, and Fz show a gradual trend with an increase in $\mathrm{f}_{\mathrm{z}}$ ranging from 0.01 to $0.08 \mathrm{~mm} / \mathrm{z}$. Similarly, whether the condition of CM or UVAM, the results in Figure 3 indicate that the cutting force of three directions also increases with an increase in $a_{p}$. Some studies have reported that a higher cutting parameter leads to a higher milling force $[26,27]$, which can be attributed to increasing the sectional area of cutting layer.

According to the experimental results shown in Figures 2 and 3, it can be seen that UVAM can effectively decrease the cutting force as compared with that of $\mathrm{CM}$ at the same cutting parameters. Moreover, as compared with $\mathrm{CM}$, when the $\mathrm{f}_{\mathrm{Z}}$ ranged from 0.01 to $0.08 \mathrm{~mm} / \mathrm{z}$, the $\mathrm{F}_{X}$, $\mathrm{F}_{Y}$ and $\mathrm{F}_{Z}$ of UVAM were reduced by $0.8 \sim 4.1 \%, 0.3 \sim 2.8 \%$, and $3 \sim 42 \%$, respectively. As compared with $C M$, when the milling depth ranged from 0.1 to $0.5 \mathrm{~mm} / z$, the $F_{X}, F_{Y}$ and $F_{Z}$ of UVAM were reduced by $5.3 \sim 27 \%, 3.8 \sim 41.2 \%$, and $29.5 \sim 65 \%$, respectively.

These above results indicate that the UVAM method has a better cutting effect by reducing the cutting force as compared with that of the $\mathrm{CM}$, which can contribute to reducing cutting friction and improving the cutting performance. The reason for the lower cutting friction using the UVAM method could be explained from the perspective of a reduction in its intermittent cutting [28].

\subsection{The Influence of UVAM on Surface Quality}

Surface roughness was measured and analyzed after CM and UVAM. The value of surface roughness was measured three times. In this part of the experiment, several groups of cutting parameters were listed in Table 2.

Figure 4 demonstrates the comparison results of surface roughness under the conditions of CM and UVAM; The measured values show that the Ra of UVAM is lower at the same cutting parameter ranging from No. 1 to No. 6. Moreover, as compared with CM at the same cutting parameter ranging from No. 1 to No. 6, the surface roughness of UVAM was reduced by $13.63 \%, 25.41 \%, 33.08 \%, 19.10 \%, 10.82 \%$, and $20 \%$, respectively.

The improvement of surface roughness using UVAM may be explained from the perspective of the real friction time, which is shorter than the separation time between them, which can contribute to reducing cutting friction and improving the quality of machined surfaces to a certain degree.

Table 2. Several groups of cutting parameters.

\begin{tabular}{cccc}
\hline Number & $\mathbf{a}_{\mathbf{p}}(\mathbf{m m})$ & $\mathbf{f}_{\mathbf{z}}(\mathbf{m m} \mathbf{z})$ & $\mathbf{n}(\mathbf{r p m})$ \\
\hline No. 1 & 0.3 & 0.03 & 4000 \\
No. 2 & 0.3 & 0.03 & 8000 \\
No. 3 & 0.3 & 0.03 & 10,000 \\
No. 4 & 0.3 & 0.01 & 6000 \\
No. 5 & 0.3 & 0.05 & 6000 \\
No. 5 & 0.3 & 0.03 & 6000 \\
\hline
\end{tabular}



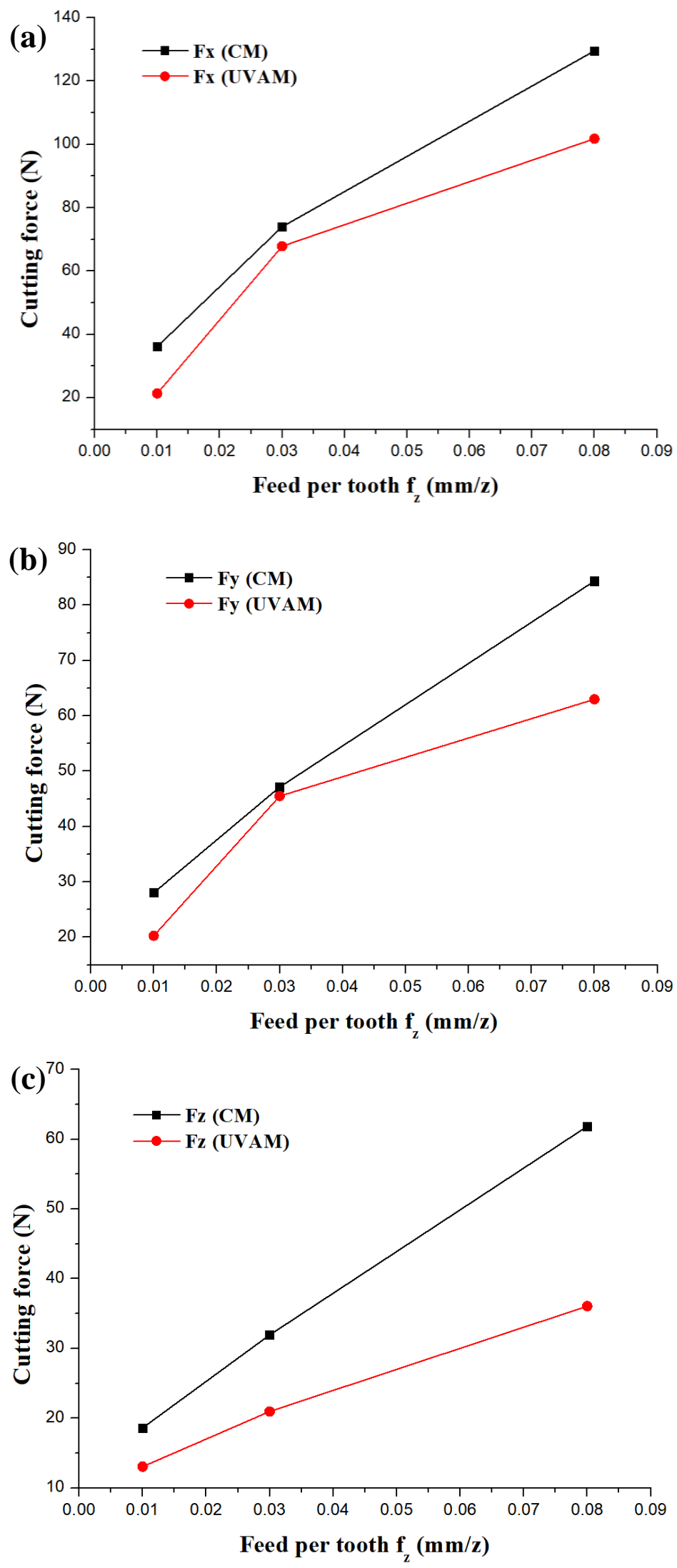

Figure 2. Influence of $\mathrm{f}_{\mathrm{z}}$ on the cutting force of CM and UVAM. (a) changing trend of $\mathrm{Fx}$, (b) changing trend of Fy, (c) changing trend of Fz. 

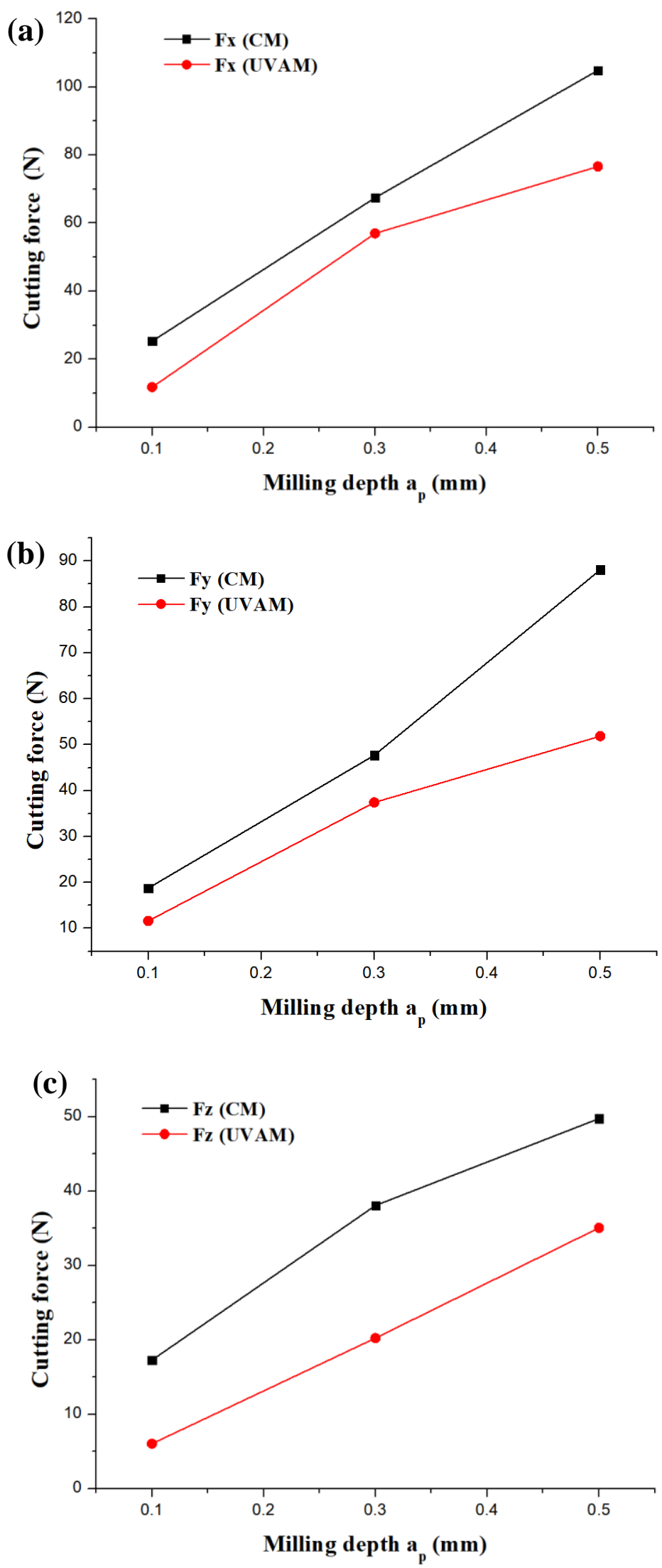

Figure 3. Influence of $\mathrm{a}_{\mathrm{p}}$ on the cutting force of CM and UVAM. (a) changing trend of $\mathrm{Fx}$, (b) changing trend of Fy, (c) changing trend of Fz. 


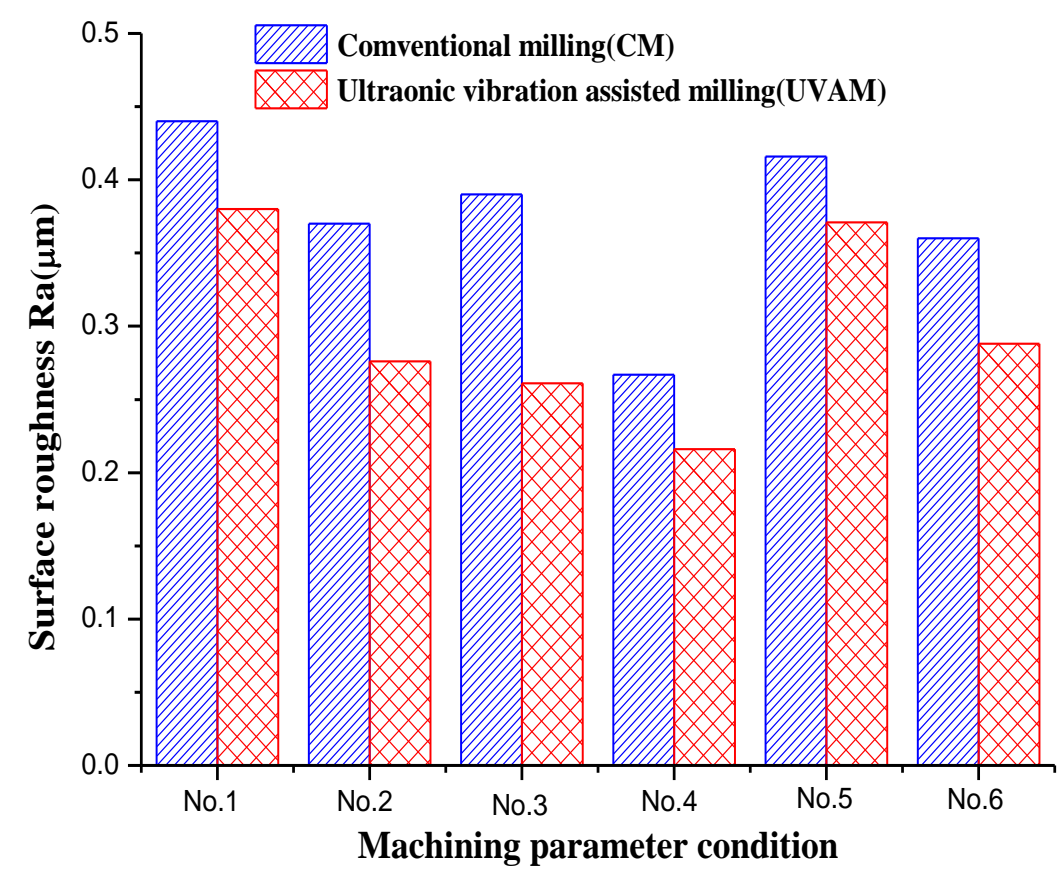

Figure 4. Comparison of surface roughness under different parameters.

The partial SEM topography of Figure 4 is illustrated in Figure 5. The images in Figure $5 \mathrm{a}$,c,e were obtained under the condition of CM, and the SEM images in Figure $5 b, d, f$ were obtained under the condition of UVAM. In addition, Figure $5 \mathrm{a}, \mathrm{b}$ employs the same cutting parameter of No. 1, the cutting parameter of Figure $5 c$, d is No.4, and the cutting parameter of Figure 5e,f is No. 6. It can be observed in Figure 5a,c,e that the machined surface has many scratches under the condition of CM, whereas, as can be seen in Figure $5 b, d, f$, the machined surface is smoother under the condition of UVAM. The above results indicate that a better machined surface and surface quality can be gained by UVAM as compared with that of $\mathrm{CM}$ at the same cutting parameter.

\subsection{Surface Adhesion of UVAM}

It can be observed from the PCD tool that there is a layer of adhesion material after the ultrasonic-assisted dry milling of the titanium alloy. Figures 6 and 7 show the energy dispersive X-ray spectroscopy (EDS) map and results of the adhesion material on the surface of the PCD tool. The results indicate that the main elements of the EDS map of Figure 6a-f include titanium, carbon, aluminum, tungsten, and cobalt. It can be concluded that the carbon, tungsten, and cobalt came from the PCD tool, and the titanium and the aluminum came from the titanium alloy. In order to further analyze the surface adhesion material, shown in Figure 6g, the analysis results of the EDS in the selected circle area M are shown in Figure $6 \mathrm{~h}$. On the basis of the above results, we can confirm that the adhesive materials of Figure $6 \mathrm{~g}$ came from the workpiece.

According to the analysis results of Figure 7a-g, we can confirm that the adhesive material on the flank face also came from the titanium alloy workpiece. Therefore, according to the results of Figures 6 and 7, it can be found that there is still a lot of chip adhesion on the surface even under the condition of UVAM. 
(a) $\mathrm{CM}$

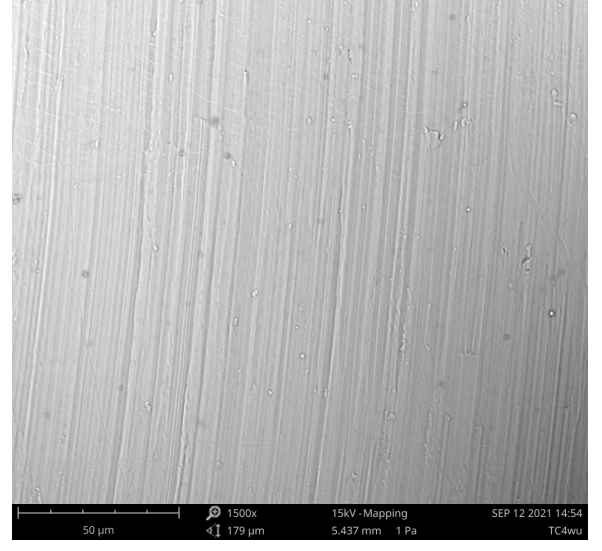

(a) and (b): $\operatorname{No.1}\left(a_{p}=0.3 \mathrm{~mm}, f_{z}=0.03 \mathrm{~mm} / \mathrm{z}, \mathrm{n}=4000 \mathrm{rpm}\right)$ (b) UVAM

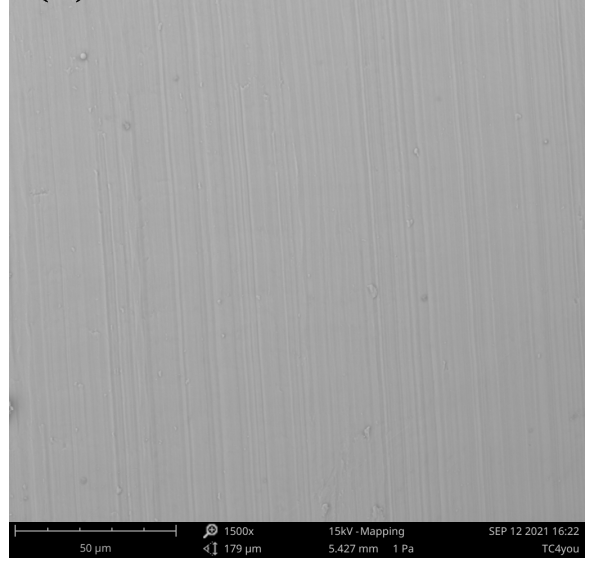

(d) UVAM

\section{(c) $\mathrm{CM}$}

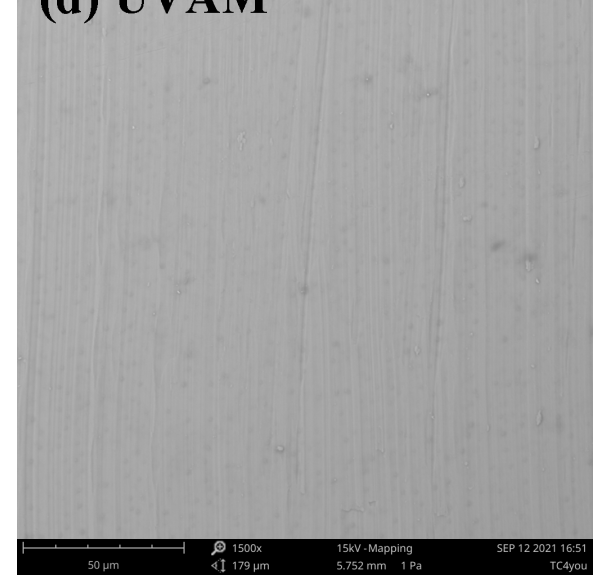

(c) and (d): No.4 $\left(a_{p}=0.3 \mathrm{~mm}, f_{z}=0.01 \mathrm{~mm} / \mathrm{z}, \mathrm{n}=6000 \mathrm{rpm}\right)$

(e) $\mathrm{CM}$

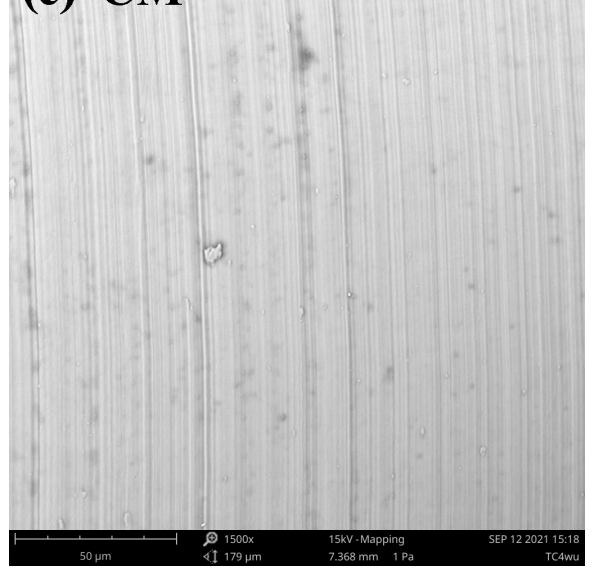

(f) UVAM

(e) and (f): $\operatorname{No.6}\left(a_{p}=0.3 \mathrm{~mm}, f_{z}=0.03 \mathrm{~mm} / \mathrm{z}, \mathrm{n}=6000 \mathrm{rpm}\right)$

Figure 5. SEM topography $(1500 \times)$ of the machined surface under CM and UVAM. 

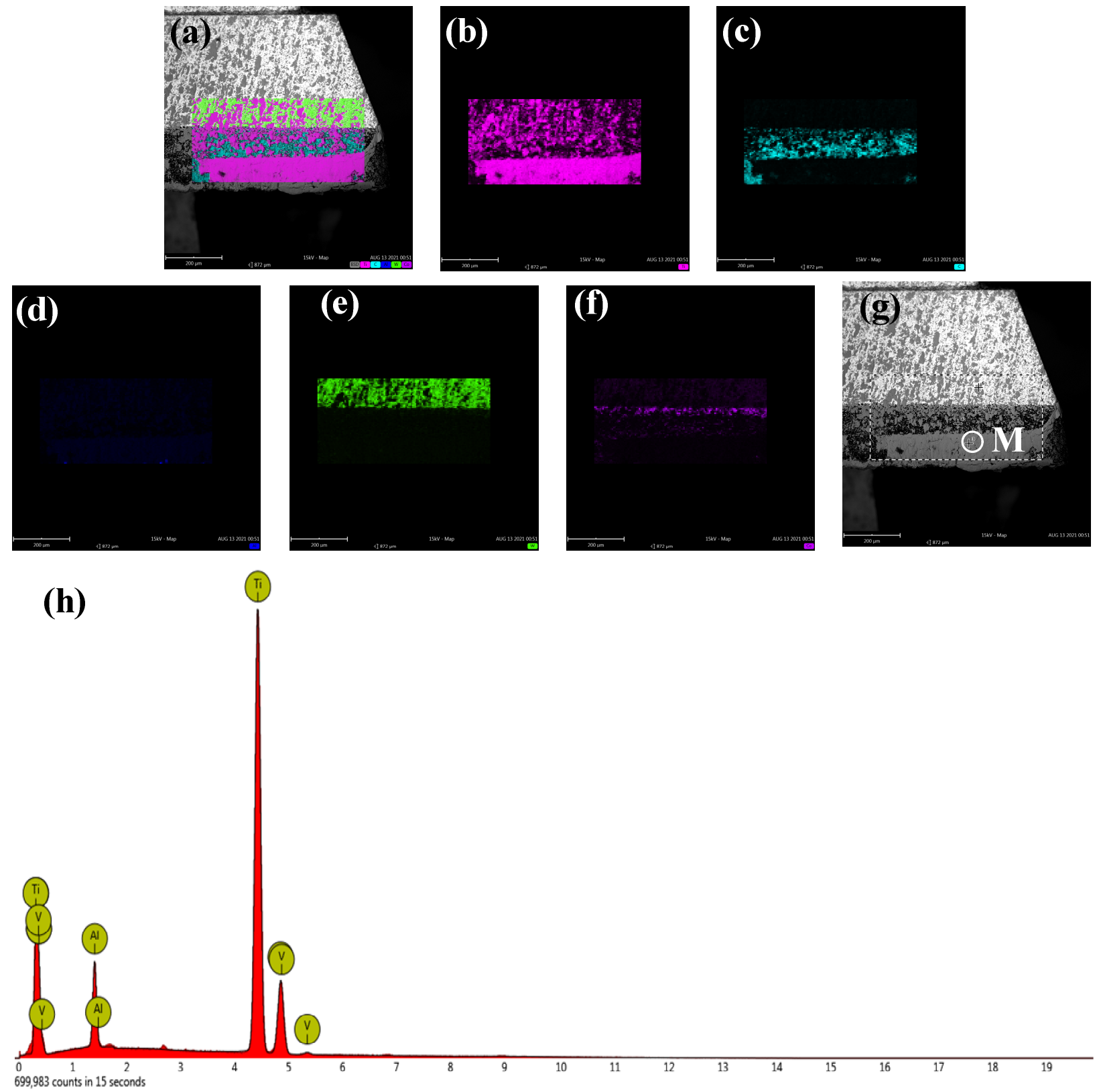

Figure 6. Element distribution and EDS of the flank face in ultrasonic-assisted milling: (a) combined map; (b) titanium; (c) carbon; (d) aluminum; (e) tungsten; (f) cobalt; (g) flank face; (h) EDS analysis of point M. 

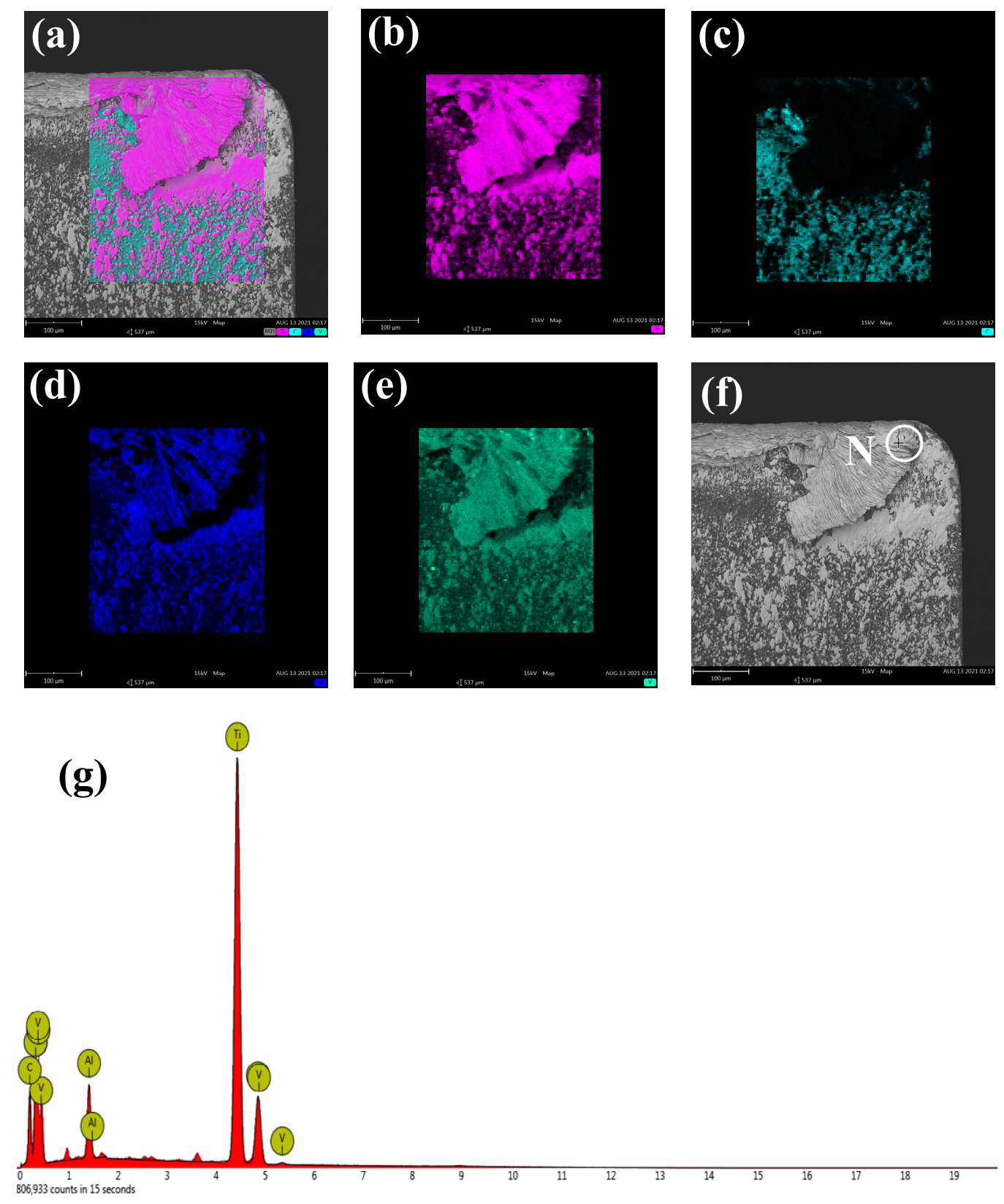

Figure 7. Element distribution and EDS of rake face in ultrasonic-assisted milling: (a) combined map; (b) titanium; (c) carbon; (d) aluminum; (e) vanadium; (f) rake face; (g) EDS analysis of point N.

\subsection{Tool Wear of UVAM}

In this study, all ultrasonic cutting tests were performed by one PCD tool, and the anti-wear of PCD tool was investigated after finishing all the ultrasonic cutting tests. The chip adhesion materials of the PCD tool were corroded for a better effect of obsevation. The SEM images of wear after ultrasonic-assisted dry milling are shown in Figure 8. In this study, the cutting length is about $612 \mathrm{~mm}$. It can be observed that there are tiny fragment and chips on the flank face and that there is almost no wear on the rake face, which may be attributed to the excellent anti-wear of the PCD tool, the shorter cutting length, and the UVAM with characteristics of intermittent cutting, etc. Therefore, the PCD tool shows good anti-wear performance in this cutting conditions. 

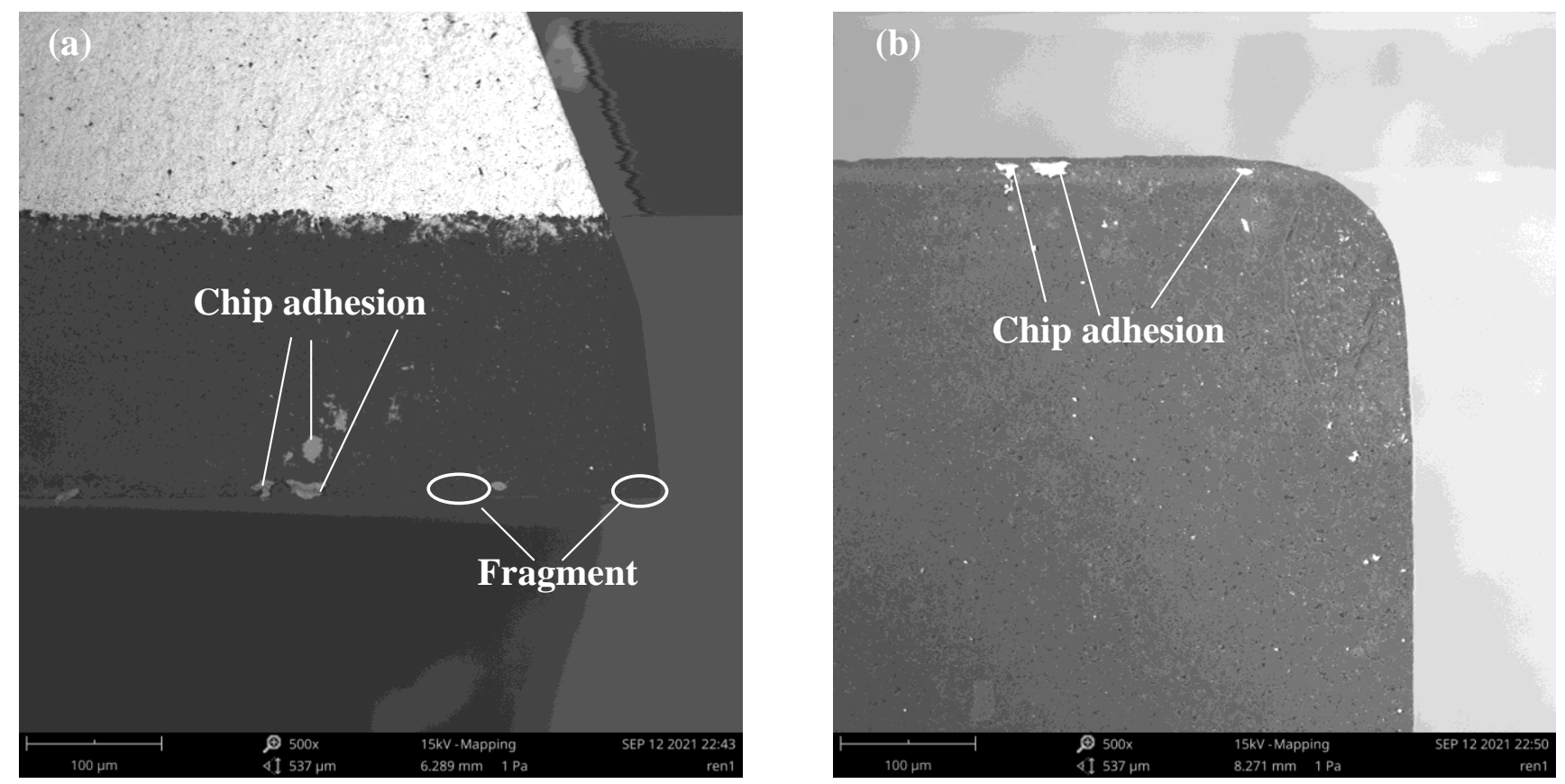

Figure 8. PCD tool wear of UVAM: (a) flank face; (b) rake face.

\subsection{Discussion on Effect of UVAM}

The above experimental results demonstrated that UVAM has a significant role in improving cutting performance and there are some main perspectives on its action mechanism.

As compared with that of CM, UVAM has less actual cutting time, which can be attributed to its intermittent cutting. Therefore, UVAM has a much longer time of complete separation time between tool-workpiece and tool-chip, and thereby produces lower cutting force and better machined surface [29]. Some studies have reported that the action mechanism of UVAM in reducing cutting force could be mainly attributed to intermittent cutting, and the results have demonstrated that the cutting force of PCD tool and surface roughness of machined surface using UVAM could be decreased by up to $40 \%$ and $30 \%$, respectively [17].

In addition, UVAM with characteristics of intermittent cutting can improve the machined surface [30] mainly because of two aspects. Firstly, the less cutting force reduces the cutting friction on the interface of the tool-workpiece, and thereby decreases the damage to the machined surface. Secondly, the characteristics of intermittent cutting in UVAM has a significant effect of chip breaking, which can decrease the chip entanglement, and thus improve the machined surface.

\section{Conclusions}

This experiments investigated the machinability difference of titanium alloys using a PCD tool under CM and UVAM. Several conclusions are summarized from the study:

1. Compared with the CM method, the UVAM method can effectively decrease the cutting force even under dry milling, and when the selected value of $f_{z}$ and $a_{p}$ ranged from low to high, respectively, the corresponding cutting force of UVAM was reduced by up to $0.8-42 \%$ and $5.3-65 \%$, respectively.

2. Compared to CM, UVAM can effectively reduce surface roughness, Ra, and the surface roughness can be reduced by $10.82-37.97 \%$ under the cutting condition of this study. The results demonstrate that UVAM is superior to CM in improving surface quality even under the dry milling condition.

3. Under the condition of UVAM, the experimental results indicate that there is serious adhesion on the PCD tool, and there is only wear of tiny fragment on its flank face. 
4. The machining mechanism of UVAM can be mainly explained from the perspective of a reduction in actual contact time and an increase in separation time between the tool-workpiece and tool-chip owing to ultrasonic vibration with the characteristic of intermittent cutting.

Author Contributions: Y.S. designed and conducted the ideas, methodology, milling experiments, and writing—original draft; L.L. guided the experimental process and some grammar. All authors have read and agreed to the published version of the manuscript.

Funding: This work was funded by support from the Natural Science Foundation of Anhui Province of China (1808085ME117), Cultivating Outstanding Talents in Colleges and Universities (gxgnfx2019013), New Material Preparation and Printing Process Development Based on SLM (2020ybxm03), and the Young and Middle-Aged Top Talent Program of Anhui Polytechnic University.

Conflicts of Interest: The authors declare no conflict of interest.

\section{References}

1. Liang, X.L.; Liu, Z.Q.; Wang, B. State-of-the-art of surface integrity induced by tool wear effects in machining process of titanium and nickel alloys: A review. Measurement 2018, 132, 150-181. [CrossRef]

2. Ezugwu, E.O.; Bonney, J.; Yamane, Y. An overview of the machinability of aeroengine alloys. J. Mater. Process. Technol. 2003, 134, 233-253. [CrossRef]

3. Hourmand, M.; Sarhan, A.A.D.; Sayuti, M.; Hamdi, M. A Comprehensive Review on Machining of Titanium Alloys. Arab. J. Sci. Eng. 2021, 46, 7087-7123. [CrossRef]

4. Lei, S.; Liu, W. High-speed machining of titanium alloys using the driven rotary tool. Int. J. Mach. Tools Manuf. 2002, 42, 653-661. [CrossRef]

5. Jawaid, A.; Koksal, S.; Sharif, S. Cutting performance and wear characteristics of PVD coated and uncoated Carbide tools in face milling Inconel 718 aerospace alloy. J. Mater. Process. 2001, 116, 2-9. [CrossRef]

6. Wang, Z.G.; Rahman, M.; Wong, Y.S. Tool wear characteristics of binderless CBN tools used in high-speed milling of titanium alloys. Wear 2005, 258, 752-758. [CrossRef]

7. Lü, W.Z.; Li, G.J.; Zhou, Y.Y.; Liu, S.Y.; Wang, K.; Wang, Q. Effect of high hardness and adhesion of gradient TiAlSiN coating on cutting performance of titanium alloy. J. Alloy. Compd. 2020, 820, 153137. [CrossRef]

8. Lindvall, R.; Lenrick, F.; Persson, H.; M'Saoubi, R.; Ståhl, J.E.; Bushlya, V. Performance and wear mechanisms of PCD and pcBN cutting tools during machining titanium alloy Ti6Al4V. Wear 2020, 454-455, 1-16. [CrossRef]

9. Kumar, U.; Senthil, P. A comparative machinability study on titanium alloy Ti-6Al-4V during dry turning by cryogenic treated and untreated condition of uncoated WC inserts. Mater. Today Proc. 2020, 27, 2324-2328. [CrossRef]

10. Denkena, B.; Lucas, A.; Bassett, E. Effects of the cutting edge microgeometry on tool wear and its thermo-mechanical load. CIRP Ann. 2011, 60, 73-76. [CrossRef]

11. Yang, Y.F.; Su, Y.S.; Li, L.; He, N.; Zhao, W. Performance of cemented carbide tools with micro-grooves in Ti-6Al-4V titanium alloy cutting. Int. J. Adv. Manuf. Technol. 2015, 76, 1731-1738. [CrossRef]

12. Wu, X.; Zeng, K.; Zhong, L.; Shen, J.Y.; Li, L. Hybrid micro-milling assisted with laser oxidation based on the hardness reduction that caused by cemented carbide oxidation. Ceram. Int. 2021, in press. [CrossRef]

13. Chen, N.; Li, H.N.; Wu, J.M.; Li, Z.J.; Li, L.; Liu, G.Y.; He, N. Advances in micro milling: From tool fabrication to process outcomes. Int. J. Mach. Tools Manuf. 2021, 160, 103670. [CrossRef]

14. Chen, N.; Li, L.; Wu, J.; Qian, J.; He, N.; Reynaerts, D. Research on the ploughing force in micro milling of soft-brittle crystals. Int. J. Mech. Sci. 2019, 155, 315-322. [CrossRef]

15. Gao, G.F.; Xia, Z.W.; Su, T.T.; Xiang, D.H.; Zhao, B. Cutting force model of longitudinal-torsional ultrasonic-assisted milling Ti-6Al-4V based on tool flank wear. J. Mater. Process. Technol. 2021, 291, 1-16. [CrossRef]

16. Chen, J.; Ming, W.W.; An, Q.L.; Chen, M. Mechanism and feasibility of ultrasonic-assisted milling to improve the machined

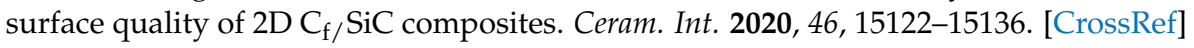

17. Ni, C.B.; Zhu, L.D. Investigation on machining characteristics of TC4 alloy by simultaneous application of ultrasonic vibration assisted milling (UVAM) and economical-environmental MQL technology. J. Mater. Process. Technol. 2020, 278, 116518. [CrossRef]

18. Ni, C.B.; Zhu, L.D.; Yang, Z.C. Comparative investigation of tool wear mechanism and corresponding machined surface characterization in feed-direction ultrasonic vibration assisted milling of Ti-6Al-4V from dynamic view. Wear 2019, 436-437, 203006. [CrossRef]

19. Lu, Z.H.; Zhang, D.Y.; Zhang, X.Y.; Peng, Z.L. Effects of high-pressure coolant on cutting performance of high-speed ultrasonic vibration cutting titanium alloy. J. Mater. Process. Technol. 2020, 279, 116584. [CrossRef]

20. Su, Y.S.; Li, L.; Wang, G.; Zhong, X.Q. Cutting mechanism and performance of high-speed machining of a titanium alloy using a super-hard textured tool. J. Manuf. Process. 2018, 34, 706-712. [CrossRef] 
21. Su, Y.S.; Li, Z.; Li, L.; Wang, J.B.; Gao, H.; Wang, G. Cutting performance of micro-textured polycrystalline diamond tool in dry cutting. J. Manuf. Process. 2017, 27, 1-7. [CrossRef]

22. Nabhani, F. Machining of aerospace titanium alloys. Robot. Comput. -Integr. Manuf. 2001, 17, 99-106. [CrossRef]

23. da Silva, R.B.; Álisson, R.M.; Ezugwu, E.O.; Bonney, J.; Sales, W.F. Tool life and wear mechanisms in high speed machining of Ti-6Al-4V alloy with PCD tools under various coolant pressures. J. Mater. Process. Technol. 2013, 213, 1459-1464. [CrossRef]

24. Ezugwu, E.O.; Bonney, J.; da Silva, R.B.; Çakir, O. Surface integrity of finished turned Ti-6Al-4V alloy with PCD tools using conventional and high pressure coolant supplies. Int. J. Mach. Tools Manuf. 2007, 47, 884-891. [CrossRef]

25. Ramirez, C.; Ismail, A.I.; Gendarme, C.; Dehmas, M.; Aeby-Gautier, E.; Poulachon, G.; Rossi, F. Understanding the diffusion wear mechanisms of WC-10\% Co carbide tools during dry machining of titanium alloys. Wear 2017, 390-391, 61-70. [CrossRef]

26. Shi, Q.; Li, L.; He, N.; Zhao, W.; Liu, X.L. Experimental study in high speed milling of titanium alloy TC21. Int. J. Adv. Manuf. Technol. 2013, 64, 49-54. [CrossRef]

27. Krishnaraj, V.; Samsudeensadham, S.; Sindhumathi, R.; Kuppan, P. A study on high speed end milling of titanium alloy. Procedia Eng. 2014, 97, 251-257. [CrossRef]

28. Shen, X.H.; Zhang, J.H.; Li, H.; Wang, J.J.; Wang, X.C. Ultrasonic vibration-assisted milling of aluminum alloy. Int. J. Adv. Manuf. Technol. 2012, 63, 41-49. [CrossRef]

29. Vermaa, G.C.; Pandey, P.M. Machining forces in ultrasonic-vibration assisted end milling. Ultrasonics 2019, 94, 350-363. [CrossRef]

30. Peng, Z.L.; Zhang, X.Y.; Zhang, D.Y. Effect of radial high-speed ultrasonic vibration cutting on machining performance during finish turning of hardened steel. Ultrasonics 2021, 111, 106340. [CrossRef] [PubMed] 